Voix et Images

voixetimages

\title{
Mémère Kerouac ou la revanche du berceau en Franco-Américanie
}

\section{Claire Quintal}

Volume 13, numéro 3 (39), printemps 1988

Jack Kerouac et l’imaginaire québécois

URI : https://id.erudit.org/iderudit/200727ar

DOI : https://doi.org/10.7202/200727ar

Aller au sommaire du numéro

Éditeur(s)

Université du Québec à Montréal

ISSN

0318-9201 (imprimé)

1705-933X (numérique)

Découvrir la revue

Citer cet article

Quintal, C. (1988). Mémère Kerouac ou la revanche du berceau en Franco-Américanie. Voix et Images, 13(3), 397-401.

https://doi.org/10.7202/200727ar d'utilisation que vous pouvez consulter en ligne.

https://apropos.erudit.org/fr/usagers/politique-dutilisation/ 


\title{
Mémère Kerouac ou la revanche du berceau en Franco-Américanie 1
}

\author{
par Claire Quintal, Institut français, Assumption College, \\ Worcester, Mass.
}

Pis c'était pareil comme rester au Canada, on mangeait des cortons, des tourquiéres... et pis...j'parlais pas l'anglais avant j'avais six ans.

Jack Kerouac, le Sel de la semaine, Radio-Canada, printemps 1967.

N'importe, Jack, que tu n'aies pas fait bonne figure à la télé québécoise en 1967, tu es, tu étais quand même un enfant du pays. Tes cousins ne t'ont pas reconnu parce que tu n'avais pas fait le même chemin qu'eux. Ils ne sont pas allés au-delà de ton joual lowellois et de ton aspect de buveur de bière et d'habitué des salles de billard. Il leur aurait fallu mieux savoir leur histoire afin de reconnaître en toi le cousin, émigré outre-frontière.

Jack Kerouac était resté au fond de lui-même un gars de Saint-Hubert (village paternel) et de Saint-Pacôme (terre maternelle) - en tout cas un gars du Québec - de ce qu'il appelle cette terre de loups?

Il savait si bien l'histoire de sa famille qu'il en parlait souvent dans ses livres (Visions de Gérard, Doctor Sax ${ }^{3}$, Vanity of Duluoz ${ }^{4}$ ), même quand on s'y attendait le moins (voir les pages liminaires de Lonesome Traveler ${ }^{5}$ ).

Tous s'est passé pour la famille Kerouac comme si elle avait écouté attentivement Lorenzo Surprenant venu au Québec parler de la magie mystérieuse des cités américaines 6.

Imaginons même un instant Maria Chapdelaine disant oui à Lorenzo Surprenant et venant habiter Lowell avec son nouveau mari. Elle y serait arrivée

1 Une version de ce texte a été présentée dans le cadre du colloque de l'International Council for Francophone Studies, tenu à Montréal en avril 1988.

2 Jack Kerouac, Visions de Gérard, Paris, Gallimard, 1972, p. 214.

3 Jack Kerouac, Doctor Sax, New York, Grove Press, 1977.

4 Jack Kerouac, Vanity of Duluoz, New York, G.P. Putnam's Sons, 1979.

5 Jack Kerouac, Lonesome Traveler, New York, Grove Press, 1977.

6 Louis Hémon, Maria Chapdelaine, Paris, Bernard Grasset, 1924, p. 182. 
vers 1913, date de la publication du roman de Louis Hémon. Elle aurait donc pu avoir comme enfants, Gérard, né en 1917, Caroline, née en 1919, et Ti-Jean, né en 1922.

Du départ des Kerouac du Québec, Jack dira que cela constituait une histoire complète à elle seule?:

[...] l'histoire d'Émile, ses frères et ses sours en colère, toute la troupe descendant de la ferme stérile vers les usines des U.S.A. 8.

C'est de ce Québec-là, celui du toumant du siècle, que Kerouac, enfant, avait entendu parler. Il faut lire attentivement les descriptions du Québec faites par Kerouac si l'on veut comprendre pourquoi tant de Canadiens français l'ont quitté:

\section{[...] ces lieux parfaitement désespérés9.}

Des vents qui ont parcouru tout ce chemin, depuis les naseaux de l'élan, les besoins grossiers, coriaces, rudes, dans les champs de pommes de terre...10.

\section{[...] la ferme stérile 11.}

Kerouac est un gars de chez vous, aussi bien que de chez nous. Ces quartiers des villes ouvrières de la Nouvelle-Angleterre où ont été élevés la plupart des Franco-Américains étaient à l'apogée de leur concentration franco-américaine dans les années de jeunesse de Ti-Jean, ces années 20 et 30 de son enfance et de son adolescence. Victor-Lévy Beaulieu dira de Doctor Sax: Il s'agit là $[\ldots] d u$ meilleur document que l'on possède sur la vie franco-américaine des années 19203012 .

Élevé dans une des villes les plus franco-américaines de la NouvelleAngleterre et, en dépit de nombreux déménagements, vivant toujours dans les quartiers franco-américains de la ville, Ti-Jean a été un Canuck d'avant la Deuxième Guerre mondiale. Ajoutez à cela une formation scolaire et religieuse, comme celle qu'on recevait alors dans les Petits Canadas de la NouvelleAngleterre, et vous obtenez un petit Canayen. Il savait parfaitement qui il était. À propos de la chanson patriotique américaine qu'on lui faisait chanter à la prestigieuse Horace Mann School à New York il parle de song no more appropriate for me to sing (as descendant of French and Indian) ${ }^{13}$.

$7 \quad$ Visions de Gérard, op. cit., p. 126.

8 Ibid., p. 126.

9 Ibid., p. 124.

10 Ibid., p. 125.

11 Ibid., p. 126.

12 Victor-Lévy Beaulieu, Jack Kerouac: essai-poulet, Montréal, Éditions du Jour, 1972, p. 30.

13 Vanity of Duluoz, op. cit., p. 32. 
On sait par ailleurs que, formé par Lowell, Kerouac n'a jamais pu quitter cette ville, psychologiquement parlant, qu'il y revenait constamment par l'écrit aussi bien que dans la réalité - qu'il y aurait même vécu ses derniers jours si Mémère avait consenti à quitter la Floride.

Il s'agit d'une attirance désespérée pour sa ville natale: $Q u^{\prime} e s t-c e$ qui vous attire à Lowell plutôt qu'à New York ou a San Francisco? lui demande-t-on. Et Jack de répondre: Ben $j^{\prime}$ connais toute la police là 14. C'est un amour-dégoût qu'il ressent pour Lowell - ville qu'il tenta de quitter à tout prix à l'âge de 17 ans. En finissant ses études secondaires Kerouac avait en effet choisi d'aller à New York (Columbia) plutôt qu'à Boston College (voir les premiers chapitres de Vanity of Duluoz). Il appelle Lowell this stinktown of stinktowns dans son roman Maggie Cassidy. C'est toutefois cette même ville, dont il décrira par le détail, dans Doctor Sax, les rues et la rivière, qui l'attire et l'effraie tout à la fois.

Profondément autobiographique, l'œuvre de Kerouac est hantée par le fait franco-américain, par les souvenirs de Lowell, par l'appartenance à une ethnie bien précise.

Kerouac, qui, par son œuvre, a réussi à faire sien le continent tout entier, ne se sent véritablement «chez lui» que chez sa mère, surnommée «Mémère». Cette femme était son refuge et son pays. Mémère représentait à la fois le petit Canada et le grand.

Ayant perdu notre patrie - le Canada - au $18^{\mathrm{e}}$ siècle, et puis à nouveau aux $19 \mathrm{e}$ et $20 \mathrm{e}$ siècles, au moment de notre émigration vers les États-Unis 15 , nous, Franco-Américains, nous sommes créé une matrie. C'est un pays situé auprès de la mère, donc toujours possible à retrouver, du vivant de celle-ci tout au moins. Le roman le plus connu de Thomas Wolfe - auteur que Kerouac admirait beaucoup - s'intitule You Can't Go Home Again. L'Américain souffre de la difficulté, voire de l'impossibilité de réintégrer le foyer. Kerouac, le Franco-Américain, passera sa vie à le faire - à revenir à sa matrie pour y puiser la source de son être, la force d'écrire son œuvre.

Lié à sa mère toute sa vie durant, Ti-Jean se nourrira toujours à même sa substance. C'est elle qui chante des vieilles chansons, c'est elle qui lui sert son ragoût de boulettes et de la date pie avec de la crème fouettée. C'est elle qui travaillera une partie de sa vie dans une usine à chaussures afin que son Ti-Jean ait le loisir nécessaire pour écrire son œuvre. Femme de la terre, Gabrielle Ange Lévesque répétera inlassablement qu'elle aurait aimé passer sa vie entière sur une terre. Ses années de jeunesse sur la terre de son oncle avaient, selon son dire, été les plus heureuses de sa vie.

14 Entrevue avec Fernand Séguin, le Sel de la semaine, Radio-Canada, 1967.

15 Voir la perte du père dans l'œuvre de Kerouac; voir aussi sa déclaration à la fin de Visions of Cody, New York, McGraw-Hill, 1974, p. 397: I am made of loss. 
Comme Louis-Ferdinand Céline, qu'il admirait aussi, Kerouac a fait son «voyage au bout de la nuit»; mais au plus profond de cette nuit, c'est encore et toujours le visage de Mémère:

...voyant soudain... le visage de ma mère... avec des yeux impénétrables et des lèvres immobiles... c'était... une vision de l'amour de ma mère pour moi - ce visage inexpressif et inexpressif-parce-que-siprofond qui se penchait sur moi dans la vision de mon sommeil, et avec des lèvres moins comprimées que patientes comme pour dire «Pauvre Ti Léo, pauvre Ti Léo, tu souffri, les hommes souffri tant, y'ainque toi dans le monde j'va't prendre soin, j'aim'ra beaucoup t'prendre soin tous les jours mon ange.»16

Sur un autre plan, Kerouac renoue avec deux figures traditionnelles du Québécois. Par son père, il hérite des coureurs de bois. Selon lui, son premier ancêtre sur ce continent le «baron» Louis-Alexandre LeBris de Keroack, $C^{\prime} t^{\prime}$ un vieux aventurier breton. Par sa mère, il est raconteur. C'est elle, drôle comme un balai, au dire de son fils, qui enwoye des pataraffes, pis des chalivaris...17.

Quand d'aventure, Jack a le goût du large, il n'hésite pas à déménager avec sa mère en Californie, ce symbole par excellence de l'Amérique moderne. Il faut lire la description rocambolesque de ce déménagement et de ce que Mémère avait apporté: the pitiful junks of life; her essential sewing basket, her essential crucifix, and her essential family photo album 18 , pour apprécier à sa juste valeur l'importance de la mère/matrie.

Le style de Kerouac, sa prose spontanée, le porte à insérer du français dans ses écrits chaque fois que l'expression première de sa pensée se présente à lui «dans la langue». Ces mots et ces phrases varient de l'expression la plus simple à la déclaration la plus imagée et profonde - toujours mal orthographiées bien sûr. Le français est une langue que Ti-Jean écrit phonétiquement. Bien qu'il en ait appris la grammaire, c'est la langue de son enfance, celle de Gérard, qu'il utilise. C'est la langue parlée par sa mère, qui a toujours prononcé l'anglais avec l'accent québécois en accentuant la dernière syllabe ${ }^{19}$, qui lui vient à l'esprit quand il est en train d'écrire. Une voix qui l'exhorte à se ranger, à quitter Cody - hantise de sa vie et symbole de l'errance continentale: Écoute, lui dit cette voix francoaméricaine, qui est avant tout celle de sa mère, avec son accent particulier et ses expressions terre à terre, Cody ye plein d'marde; les lé allez, il est ton ami, les lé songée; yé pas ton frere, yé pas ton pere [...] La méditation de Kerouac finit par ces mots significatifs: [...] descend pas le côté de l'autre bord de ta vie pour rien 20 .

16 Jack Kerouac, les Souterrains, Paris, Gallimard, 1964, p. 177-178.

17 Le Sel de la semaine, Radio-Canada, 1967.

18 Jack Kerouac, Desolation Angels, New York, G.P. Putnam's Sons, 1979, p. 333.

19 Visions de Gérard, op. cit., p. 170.

20 Visions of Cody, op. cit., p. 362-363. 
Cette Gabrielle-Ange, à qui il ressemblait au dire de l'un de ses amis 21 allait d'ailleurs survivre à son fils - tout comme la culture franco-américaine survivra à la perte de sa langue maternelle, aussi longtemps qu'elle pourra maintenir sa matrie.

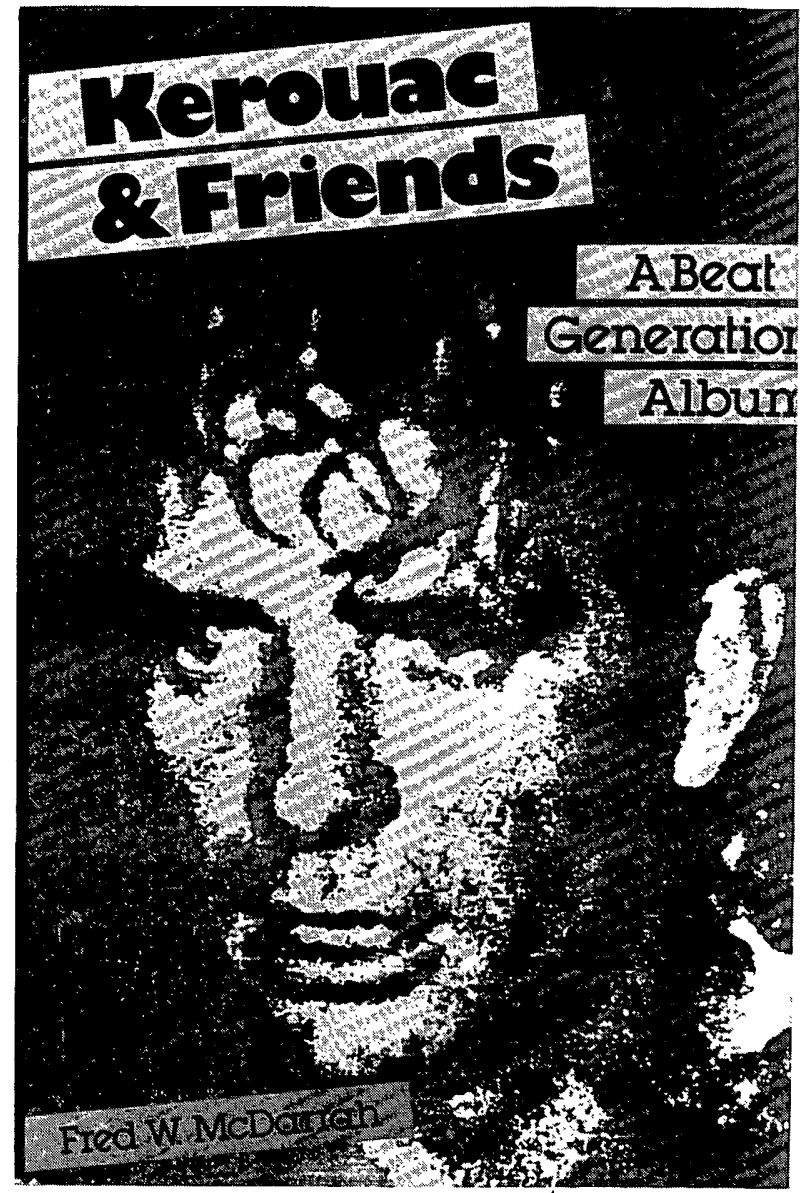

21 Barry Gifford et Lawrence Lee, Jack's Book, New York, St. Martin's, 1978, p. 257. 